\title{
Fungal diversity and metabolomic profiles in GM and isogenic non-GM maize cultivars from Brazil
}

\author{
A. M. Gasperini ${ }^{1} \cdot$ E. Garcia-Cela ${ }^{2} \cdot$ M. Sulyok $^{3} \cdot$ A. Medina $^{1} \cdot$ N. Magan ${ }^{1}$ (I)
}

Received: 27 May 2020 / Revised: 2 October 2020 / Accepted: 5 October 2020 / Published online: 12 October 2020

(C) The Author(s) 2020, corrected publication 2020

\begin{abstract}
There is little knowledge of the microbial diversity, mycotoxins and associated secondary metabolites in GM maize and isogenic non-GM cultivars (cvs). This study has quantified the microbial populations and dominant fungal genera in 6 cvs of each type representative of herbicide, pesticide or stacked resistance to both. The predominant mycotoxins and targeted metabolomics profiles were also compared between the two sets of cvs. This showed that the overall fungal populations were $8.8 \mathrm{CFUs} \mathrm{g}^{-1}$ maize. The dominant genera, isolated from maize samples, whether surface-sterilised or not, in all maize cvs were Fusarium, followed by Penicillium, Aspergillus and occasionally Cladosporium and Alternaria. The analysis of the targeted metabolomics showed that approx. 29 different metabolites were detected. These were dominated by fumonisins and minor Penicillium spp. metabolites (questiomycin A and rugulovasine A). Interestingly, the range and number of mycotoxins present in the GM cvs were significantly lower than in the non-GM maize samples. This suggests that while the fungal diversity of the two types of maize appeared to be very similar, the major contaminant mycotoxins and range of toxic secondary metabolites were much lower in the GM cvs.
\end{abstract}

Keywords Fungal diversity $\cdot$ Mycotoxigenic fungi $\cdot$ Metabolomics $\cdot$ Toxic secondary metabolites $\cdot$ Selective media $\cdot$ Maize cultivars $\cdot$ GM $\cdot$ Non-GM

\section{Introduction}

In many parts of the world, maize production has become dominated by GM cultivars (cvs) which have replaced conventional ones, especially for improving herbicide and pesticide resistance. However, fungal pathogens of maize are responsible for significant economic losses in terms of yield and nutritional quality, especially during the critical silking period up to harvest. The major foliar pathogens include rusts, leaf spots, anthracnose, mildews

N. Magan

n.magan@ cranfield.ac.uk

1 Applied Mycology Group, Environment and AgriFood Theme, Cranfield University, Cranfield, Bedfordshire MK43 0AL, UK

2 Biological and Environmental Sciences, School of Life and Medical Sciences, University of Hertfordshire, Hatfield AL10 9AB, UK

3 Institute of Bioanalytics and Agro-Metabolomics, Department of Agrobiotechnology (IFA-Tulln), University of Natural Resources and Life Sciences, Konrad Lorenzstr. 20, A-3430 Tulln, Vienna, Austria and ergot. In addition, infection of ripening cobs by Aspergillus, Penicillium and Fusarium species can cause significant quality losses as well as contaminating them with toxic secondary metabolites (mycotoxins; Battilani et al. 2013). This results in Aspergillus ear or kernel rot (caused by A. flavus) and Fusarium ear rot (caused by $F$. verticillioides, $F$. proliferatum, and $F$. subglutinans), Gibberella ear rot (caused by $F$. graminearum) (Munkvold 2014). The Aspergillus section Flavi group contaminates the maize grain with aflatoxins, Aspergillus section Circumdati species and Penicillium verrucosum with ochratoxins, and the Fusarium species with either fumonisins or type B trichothecenes. There are legislative limits for some if not all these mycotoxins worldwide, with the most stringent regulations in the EU.

In Brazil, maize represents an important economic and social product in both family farming and agribusiness (Vidal et al. 2015). The country is the second largest biotech crop producer, after the USA, and is emerging as a global leader in this sector. Soybean production is the highest, followed by maize. Brazil has been a leader in the development of different biotechnology-modified traits, including 39 for maize (ISAAA 2017). Maize is cultivated in the summer and winter months in 
Brazil, with many differences between the management during the cropping season. All three categories of GM-type maize, insect resistance (IR), herbicide tolerance (HT), and the stacked $\mathrm{IR} / \mathrm{HT}$, are cultivated in both summer and winter maize.

Thus, in Brazil, GM maize cvs have become common and have largely superseded the equivalent conventional ones. Indeed, the tropical and sub-tropical climatic regions in Brazil are favourable for mycotoxigenic fungal colonisation of maize both pre- and post-harvest. Contamination of maize with aflatoxins and fumonisins has thus been frequently reported in Brazil (Salay and Zerlotti Mercadante 2002; Kawashima and Valente Soares 2006; Moreno et al. 2009; Caldas and Oliveira 2012; Baquião et al. 2012)

The adoption of GM crops continues to increase on a global scale, and the effects on mycotoxin contamination has been to a large extent ignored ( $\mathrm{Wu} 2006)$. It has been reported that when plants were infested with Southwestern corn borers, a GM (Bt11) hybrid had $>75 \%$ reduction in aflatoxins when compared with its non-Bt counterpart (Windham et al. 1999). In Brazil, despite the large GM maize production, few surveys have investigated the similarity and differences in fungal diversity of the harvested maize grain. In addition, a relative comparison of mycotoxins and related toxic secondary metabolites of GM maize cvs with herbicide tolerance, insect resistance or both herbicide tolerance + insect resistance, and their original non-GM isogenic cvs has not been previously examined.

The objectives of this study were to examine harvested maize grain of $6 \mathrm{GM}$ and their related non-GM isogenic cvs to compare (a) moisture content when harvested and stored, (b) fungal populations and the fungal diversity and (c) mycotoxins and related secondary metabolite profiles.

\section{Materials and methods}

\section{Maize samples}

The maize samples were harvested in Brazil in two seasons (2015 and 2016) in two different states (location 1 Paraná, location 2 - Mato Grosso). Location 1 is a humid sub-tropical zone with average temperature $\geq 25{ }^{\circ} \mathrm{C}$ in the harvest season. Location 2 has a tropical climate with an average temperature $\geq 28^{\circ} \mathrm{C}$ in the harvest season. A total of six pairs of maize (conventional and its GM isogenic cv; $n=12$ ) of approximately $1 \mathrm{~kg}$ each cv were obtained. They were obtained by randomly taking smaller samples from different harvested maize plots of each cv and mixed to obtain the representative sample of each one. The samples were placed in sealed bags after harvesting and drying and sent by a courier to the Applied Mycology Group, Cranfield University, England, and stored at $4{ }^{\circ} \mathrm{C}$ until analysis. The details of the different Brazilian maize cvs examined are shown in Table 1.

\section{Measurement of moisture content of the maize samples}

Three 10-g sub-samples of each cv were weighed and placed in glass vials. These were dried in an oven at $110^{\circ} \mathrm{C}$ for $24 \mathrm{~h}$. Thereafter, they were placed in a desiccator jar containing silica gel and left to cool and the final dry weight obtained. The percentage moisture content (\%MC) was then calculated on a wet weight basis.

\section{Fungal isolation from the maize samples}

Enumeration of fungal populations The enumeration of fungi was done using the serial dilution technique based on the method of Mohale et al. (2013). Three sub-samples of each maize cv $(10 \mathrm{~g})$ were soaked for $3 \mathrm{~h}$ in a sterile Stomacher bag containing $90 \mathrm{~mL}$ of sterile distilled water supplemented with $0.05 \%(\mathrm{w} / \mathrm{v})$ technical agar (Oxoid, Basingstoake, UK) and $0.025 \%(\mathrm{w} / \mathrm{v})$ Tween 80 . The bags were homogenised for $5 \mathrm{~min}$ at high speed $(300 \mathrm{rpm} \pm 5 \%)$ in a Stomacher blender (Lab-Blender 400; Seward Medical, UK). The sample bags were transferred in beakers to the sterile flow bench and allowed to settle for $5 \mathrm{~min}$. Then, initially, using a $5-\mathrm{mL}$ sterile tip, $1 \mathrm{~mL}$ was transferred to the $10^{-2}$ dilution bottle containing $9 \mathrm{~mL}$ of sterile water $+0.01 \%$ tween 80 . Subsequently sterile $1-\mathrm{mL}$ pipette tips were used to for serial dilution to $10^{-3}$ to $10^{-5}$. Between each serial dilution the $25 \mathrm{~mL}$ Universal bottles were shaken vigorously for $60 \mathrm{~s}$. In the reverse order, $10^{-5}$ to $10^{-1}$, aliquots of $100 \mu \mathrm{L}$ from each dilution were taken using a sterile $200-\mu \mathrm{L}$ pipette tip placed centrally on the surface of the triplicate Petri dishes for each dilution. This was spread with a surface-sterilised L-shaped glass rod on the Malt Extract Agar (MEA; Thermo Fisher Scientific Oxoid Ltd., Basingstoke, Hampshire, UK) and Dichloran-Glycerol 18\% agar (DG18; Thermo Fisher Scientific Oxoid Ltd., Basingstoke, Hampshire, UK) media.

The preparation of each growth media was done according to the manufacturers' instructions using deionised water (15 $\Omega \mathrm{m})$. The media was autoclaved at $121{ }^{\circ} \mathrm{C}$ for $15 \mathrm{~min}$ at 103 $\mathrm{kPA}$, and chloramphenicol (Fisher Bioreagents, Pasley, UK) was used as an anti-bacterial agent prior to autoclaving the media. The molten media were poured into 9-cm Petri dishes (approx. $17.5 \mathrm{~mL}$ per dish).

The Petri dishes $(9 \mathrm{~cm} \varnothing)$ were incubated for 7 days at $25{ }^{\circ} \mathrm{C}$. The colonies growing in a range of 10 to 100 colonies were counted in three plates per dilution, and their numbers expressed as $\log _{10}$ colony forming units (CFUs) per gramme dry weight of maize ( $\log _{10}$ CFUs $g$ dry weight ${ }^{-1}$ ). To obtain the actual fungal load, the calculated CFUs were adjusted based on the actual dry weight of the maize kernels after drying and reported as CFUs g ${ }^{-1}$ dry weight (Mohale et al. 2013). 
Table 1 Description of the conventional (non-GM) and respective genetically modified (GM) isogenic cultivars of maize grain used in this study

\begin{tabular}{lll}
\hline Conventional cultivars (non-GM) & Isogenic GM cultivar & Traits tolerance present in the GM cvs \\
\hline AS 1555 CON & AS 1555 PRO® & Pesticide-tolerant \\
BM-709 CON & BM-709 $\mathrm{PRO}_{2}{ }^{\circledR}$ & HT - Glyphosate \\
& & R - Lepidopteran \\
CD-384 CON & CD-384 PW® & HT - Glyphosate \\
& & HT - Glufosinate ammonium \\
M20-A78 CON & M20-A78 PW® & IR - Lepidopteran \\
& & HT - Glyphosate \\
P30F53 CON & & HT - Glufosinate ammonium \\
& P30F53 H® & IR - Lepidopteran \\
& & HT - Glufosinate ammonium \\
P2530 CON & & Antibiotic resistance \\
\hline
\end{tabular}

$I R$, insect resistance; $H T$, herbicide tolerance
Frequency of isolation of fungi From each sample, 100 maize kernels were sub-sampled from each cv. Fifty (50) kernels from the sub-sample were first surface-disinfected (+SD) with sodium hypochlorite $0.4 \% \mathrm{v} / \mathrm{v}(\mathrm{NaOCl})$ for $2 \mathrm{~min}$, left to dry and then plated, five maize kernels equidistant from each other on each Petri dish. The remaining kernels were plated without surface disinfection (-SD) in the same way. The kernels were directly plated (25 kernels per medium; five kernels per Petri dish) on DG18 and MEA media. The Petri dishes were incubated at $25{ }^{\circ} \mathrm{C}$ for $7-10$ days, then inspected visually for fungal growth.

The fungal occurrence, i.e., number of maize grains from which Aspergillus sections Flavi, Nigri, and Circumdati, Penicillium and Fusarium and other fungi grew, was noted. To obtain the isolation frequency (\%), all fungal colonies growing from directly plated kernels on MEA and DG18 were recorded.

\section{Identification of mycotoxins and other targeted metabolomic profiles of the GM and non-GM maize cultivars using LC-MS/MS}

A multi-targeted metabolomics approach was used to identify the mycotoxins present in the maize samples. For these studies, the analysis was performed in duplicate for each cv because of the limited amount of maize available. The milled sub-samples ( $5 \mathrm{~g}$ ) of maize were extracted using $20 \mathrm{~mL}$ extraction solvent (acetonitrile: water: acetic 79:20:1 (v/v/v) followed by a $1+1$ dilution using acetonitrile: water: acetic 20:79:1 (v/v/v). Five microliters of the diluted extract was directly injected into the sampling port for LC-MS/MS in the equipment for analysis (Sulyok et al. 2020). A QTrap 5500 LC-MS/MS System (Applied Biosystems, Foster City, CA) equipped with a Turbo Ion Spray electrospray ionisation (ESI) source and a 1290 Series HPLC System (Agilent,
Waldbronn, Germany). Chromatographic separation was performed at $25{ }^{\circ} \mathrm{C}$ on a Gemini® $\mathrm{C}_{18}$-column, $150 \times 4.6 \mathrm{~mm}$ i.d., 5- $\mu \mathrm{m}$ particle size, equipped with a $\mathrm{C}_{18} 4 \times 3 \mathrm{~mm}$ i.d. security guard cartridge (all from Phenomenex, Torrance, CA, USA). The chromatographic method and the chromatographic and mass spectrometric parameters were previously described by Malachová et al. (2014) and Sulyok et al. (2020). ESI-MS/ MS was performed in the time-scheduled multiple reaction monitoring (MRM) mode both in positive and negative polarities in two separate chromatographic runs per sample by scanning two fragmentation reactions per analyte.

Quantification of the secondary fungal metabolites and mycotoxins was performed via external calibration using serial dilutions of a multi-analyte standard stock solution. The method covered all the mycotoxins addressed by regulatory limits as well as a range of other secondary metabolites. The reference standards for mycotoxins and other fungal metabolites are detailed by Sulyok et al. (2020). Results were corrected for recoveries obtained during method validation. The accuracy of the method has been verified on a continuous basis by regular participation in proficiency testing schemes (Sulyok et al. 2020). This approach has been previously applied to targeted metabolomics in cereal samples (Garcia-Cela et al. 2018).

\section{Statistical analysis and data sets}

Data sets were subjected to Shapiro-Wilk tests to determine normality and Levene's test to assess the equality of variance. The percentage moisture content (\%MC) satisfied the two assumptions after transformation to cube root. Afterwards, one-way analysis of variance (ANOVA) was performed. The colony forming units (CFUs), frequency of fungal isolation and secondary metabolites data violated the two assumptions of ANOVA even after transformations, and consequently non-parametric tests (Wilcoxon/Kruskal-Wallis; $p=0.05$ ) 
were used for analyses (Chan and Walmsley 1997). Where there was significance after the Kruskal-Wallis test, median comparisons for each pair of the different cvs were made using the Wilcoxon - Each Pair test $(p=0.05)$, while significance in ANOVA was done by comparisons of the means using Tukey HSD $\left(p=0.05\right.$ ). The statistical package JMP ${ }^{1} 4$ (SAS Institute Inc., 2018, Cary NC, USA) was used to perform the analyses.

All the primary data sets from this manuscript are held by Cranfield University and are openly accessible via the corresponding author.

\section{Results}

\section{Moisture content of the GM and non-GM cultivars}

The moisture content (MC, \% wet weight) was between 11 and 22\% (Fig. 1). The recommended conditions for safe storage of maize are $\mathrm{MC} \leq 15 \%$ ( $=\leq 0.70$ water activity). Most of the samples were within the safety levels for storage without any potential for mould spoilage initiation. Significant differences at Tukey-Kramer HSD $(p<0.05)$ were found for two of the 12 cvs.

\section{Enumeration of the fungal populations isolated from the GM and non-GM maize samples}

The GM and non-GM maize samples examined in this study had relatively high levels of total culturable fungal populations. The overall total fungal populations isolated from all cvs were $<8.8 \log _{10} \mathrm{CFUs} \mathrm{g}^{-1}$ (Table 2). There was no significant difference in the populations (CFUs) between the samples at the $5 \%$ significance level on either MEA or DG18 media.

\section{Frequency of isolation of dominant fungi}

Figure 2 shows the relative frequency of isolation of different dominant fungal genera from the different GM and non-GM cvs when plated without or with surface disinfection on both media. There was a higher frequency of isolation from the non-disinfected plated maize kernels than from those that were surface-disinfected (Fig. 3). The surface disinfection allowed the isolation of internal fungal colonisers from the maize kernels when directly plated on the two media. The mycological analysis showed that Fusarium, Penicillium and Aspergillus glaucus group (=Eurotium species) were the principal contaminating genera of the maize kernels from both GM and non-GM cv samples. Aspergillus section Flavi strains were isolated from eight of the $12 \mathrm{cv}$ samples. There was no significant difference $(p=0.05)$ in the frequency of isolation of the different fungi on the two-culture media (MEA $\times$ DG18) used or between non-GM and GM cvs (see Fig. 3).

\section{Mycotoxins and other secondary metabolites found in GM and non-GM cultivars of maize}

The LC-MS/MS analysis of the six GM and their isogenic non-GM maize cvs showed a higher presence of mycotoxins related to Fusarium and Penicillium spp., while toxins produced by A. flavus were largely absent. A total of 29
Fig. 1 Values of moisture content (MC, \%) of the GM and non-GM isogenic samples of maize cultivars. Bars represent the SE. The ( ) shows those cultivars which were significantly different when compared with the other cultivars using the Tukey-Kramer HSD $(p<0.05)$

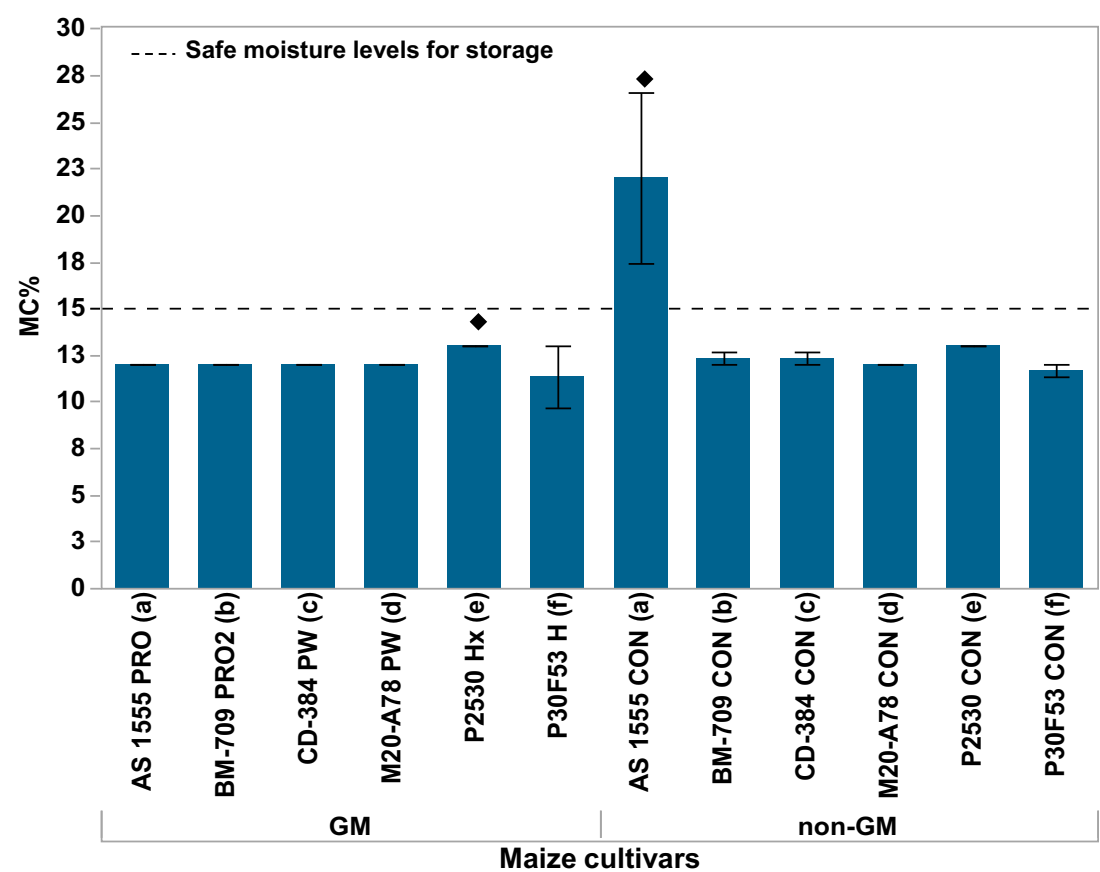


Table 2 Enumeration $\left(\log _{10} \mathrm{CFU} \mathrm{g} \mathrm{g}^{-1}\right.$ dry sample) of total fungal populations isolated from the genetically modified (GM) and non-GM cultivars

\begin{tabular}{|c|c|c|c|}
\hline Type & Cultivar & MEA & DG18 \\
\hline \multirow[t]{6}{*}{ GM } & ${ }^{1} \mathrm{AS} 1555 \mathrm{PRO} 囚$ & $7.19 \pm 0.03$ & $7.17 \pm 0.06$ \\
\hline & ${ }^{2} \mathrm{BM}^{-709} \mathrm{PRO}_{2}{ }^{\circledR}$ & $6.87 \pm 0.05$ & $6.90 \pm 0.05$ \\
\hline & ${ }^{3} \mathrm{CD} 384 \mathrm{PW}$ & $6.72 \pm 0.15$ & $5.97 \pm 0.01$ \\
\hline & ${ }^{4} \mathrm{M} 20-\mathrm{A} 79 \mathrm{PW}$ & $7.05 \pm 0.08$ & $6.91 \pm 0.15$ \\
\hline & ${ }^{5} \mathrm{P} 2530 \mathrm{Hx}{ }^{\circledR}$ & $8.14 \pm 0.03$ & $8.04 \pm 0.15$ \\
\hline & ${ }^{6} \mathrm{P} 30 \mathrm{~F} 53 \mathrm{H} \circledast$ & $8.10 \pm 0.03$ & $7.93 \pm 0.09$ \\
\hline \multirow[t]{6}{*}{ non-GM } & ${ }^{1} \mathrm{AS} 1555 \mathrm{CON}$ & $8.26 \pm 0.02$ & $8.27 \pm 0.02$ \\
\hline & ${ }^{2} \mathrm{BM}-709 \mathrm{CON}$ & $7.65 \pm 0.04$ & $6.98 \pm 0.39$ \\
\hline & ${ }^{3} \mathrm{CD} 384 \mathrm{CON}$ & $7.19 \pm 0.03$ & $7.73 \pm 0.04$ \\
\hline & ${ }^{4} \mathrm{M} 20-\mathrm{A} 79 \mathrm{CON}$ & $7.28 \pm 0.06$ & $8.23 \pm 0.03$ \\
\hline & ${ }^{5} \mathrm{P} 2530 \mathrm{CON}$ & $8.33 \pm 0.04$ & $8.79 \pm 0.04$ \\
\hline & ${ }^{6} \mathrm{P} 30 \mathrm{~F} 53 \mathrm{CON}$ & $7.77 \pm 0.02$ & $7.73 \pm 0.10$ \\
\hline
\end{tabular}

Values correspond to average $\pm \mathrm{SD}(n=3)$. Six isogenic lines were examined. No significant differences were found at $5 \%$ significance (Wilcoxon/Kruskal-Wallis test)

$M E A$, malt extract agar; DG18, Dichloran $18 \%$ Glycerol media

secondary metabolites were detected in the samples (Table 3 ). Mycotoxins of relevance in terms of food safety such as deoxynivalenol, zearalenone, trichothecens, ochratoxin A, citrinin or sterigmatocystin were not detected in the samples used in this study. An overall comparison of metabolites detected in the samples indicated that although there was no significant difference in the frequency of isolation (percentage; Fig. 3), the presence of mycotoxins was higher in the non-GM cvs (Fig. 4). Two regulated toxins (fumonisin $\mathrm{B}_{1}$ and $\mathrm{B}_{2}$; EC (2006)) were detected in higher amounts in the non-GM cvs. Comparing each cv individually, it was possible to identify marked differences between the GM and their isogenic non-GM line $(p<0.05)$ (see Table 3). For example, the non-GM cv (CD-384 CON) had the highest levels of fumonisin $\mathrm{B}_{1}\left(6480.5 \mu \mathrm{g} \cdot \mathrm{kg}^{-1}\right)$, while for its $\mathrm{GM}$ isogenic line (CD-384 PW®), the same toxin was not detected. A similar trend was found when comparing the non-GM line (P30F53 $\mathrm{CON}$ ) where fumonisin $\mathrm{B}_{1}$ was $>5000 \mu \mathrm{g} \cdot \mathrm{kg}^{-1}$, while in the GM line (P30F53 H), the toxin concentration was about $40 \times$ lower $\left(148 \mu \mathrm{g} \cdot \mathrm{kg}^{-1}\right)$.

\section{Discussion}

The majority of the samples analysed in this study had moisture content $(\% \mathrm{MC})$ levels within the safety range for storage without any fungal spoilage. There was no significant difference $(p=0.05)$ in the frequency of isolation of the different fungal genera on the two-culture media (MEA $\times$ DG18), although the latter medium selects for more xerotolerant and xerophilic species. Fusarium and Penicillium spp. were isolated in the highest frequency from all 12 cvs examined, regardless of whether they were GM or non-GM maize. There were also no differences in the dominant species when comparing GM and non-GM cvs. Samples without surface disinfection had significantly higher overall contamination suggesting field and harvesting operations contributed to the inoculum deposited on ripened maize cobs and kernels. A. flavus was isolated from a lower percentage of the samples $(<40 \%)$ than that with Fusarium species. It was interesting to note that strains isolated from non-GM cvs were mostly $\mathrm{AFB}_{1}$ producers, whereas the majority of strains from GM cvs were non-toxigenic (Gasperini 2019).

Both phyllosphere field and storage fungi were detected in the directly plated maize samples. Field fungi such as Cladosporium, Alternaria and especially Fusarium species
Fig. 2 Relative frequency of isolation (\%) of different predominant fungal genera isolated from the GM and isogenic non-GM maize cultivars. "Others" include species from the Rhyzopus, Epicocum, Cladosporium, Mucor, Alternaria, Wallemia and Trhichoderma genera. This is the combined data from both DG18 (Dichloran 18\% Glycerol) and MEA (malt extract agar) media and includes the data for nonsurface-sterilised and surfacesterilised maize kernels for each cultivar

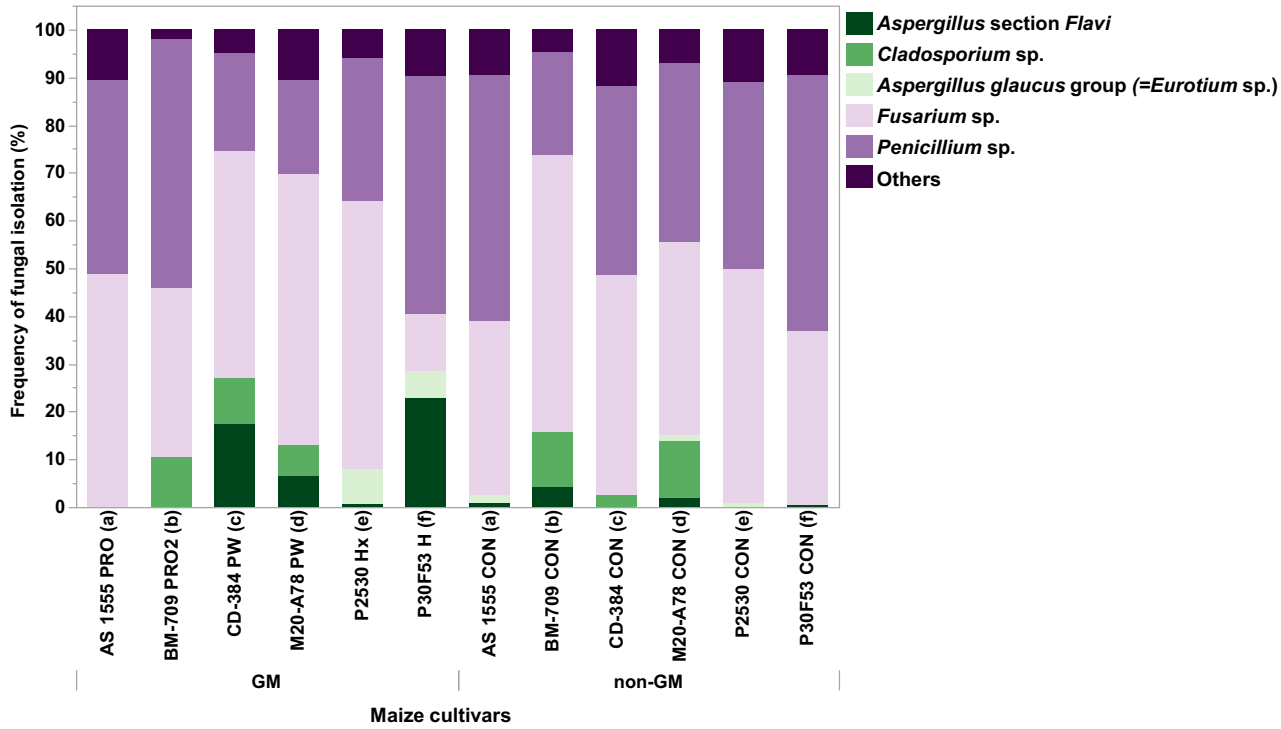


Fig. 3 Overall frequency of fungal isolation (\%) comparing non-surface-disinfected maize kernels (NO) with surface disinfection (YES); growth medium DG18 (Dichloran 18\% Glycerol) vs MEA (malt extract agar); and GM vs non-GM cultivars. $p<$ 0.05 denotes significant difference between the levels of isolation using the Wilcoxon - Each Pair test.

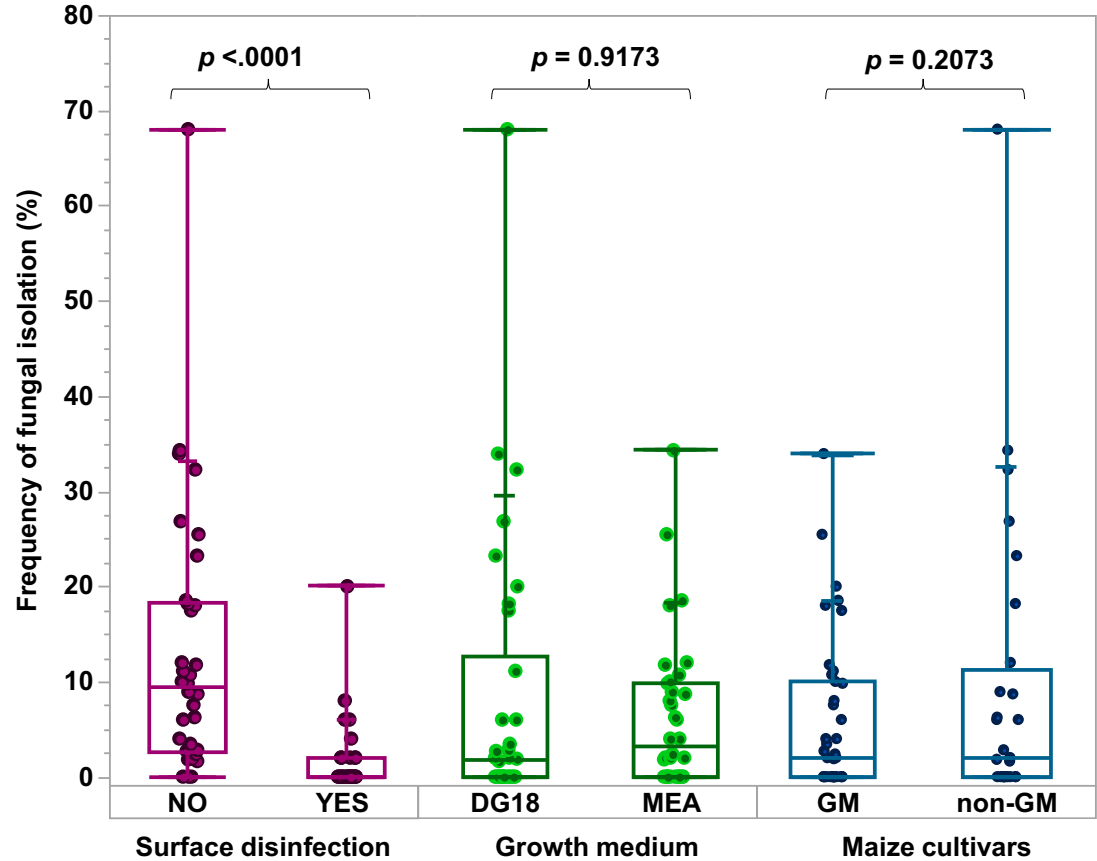

were found in these samples. Penicillium spp. were also isolated in high frequency in all the samples. Aspergillus sections Nigri and Flavi were isolated less frequently, with A. flavus being detected in eight out of the $12 \mathrm{cvs}$.

The moisture content and thus $a_{\mathrm{w}}$ of the maize kernels during the milky ripe stage is very suitable for infection by Fusarium species. Subsequently, during the dough stage, the kernels are drier allowing more opportunities for A. flavus to colonise, especially where damage has occurred due to the presence of insect pests (Gasperini et al. 2019). Of course, GM cvs which may have insect-related tolerance should in principle have more overall resistance to such mycotoxigenic pathogens (Lacey 1989; Battilani et al. 2011; Gasperini 2019).

No previous studies have examined the secondary metabolite profiles in GM and isogenic non-GM maize. The metabolomic profiles found in these two groups of cvs showed that Fusarium metabolites were present in all those examined. It is well-known that $F$. verticillioides can infect maize systemically (Munkvold and Desjardins 1997) and may also survive in an endophytic phase (Alberts et al. 2016) which may contribute to the fumonisins found in these samples. The metabolomic profiles identified was higher in the non-GM maize cvs, including concentrations of fumonisin $\mathrm{B}_{1}+\mathrm{B}_{2}$ being above the legislative limits.

Fumonisins have often been detected in Brazilian maize (Peluque et al. 2014; Bordin et al. 2015) and even in processed products such as beer (Kawashima and Valente Soares 2006; Piacentini et al. 2017). A high frequency of Fusarium spp. $(70 \%)$ was previously observed in maize hybrids in both asymptomatic and maize with visible kernel rot, resulting in total fumonisins being above the legislation limits (7240 $\mu \mathrm{g} . \mathrm{kg}^{-1}$; Lanza et al. 2017). In recent years, there has been a focus on other emerging potentially toxigenic compounds produced by Fusarium species such as fusaproliferin, beauvericin, enniatins and moniliformin. Limited data are available on their toxicity (Jestoi 2008), and so far, no firm conclusions have been drawn regarding in vivo toxicity to elaborate a human risk assessment (EFSA 2014). However, some in vitro studies have suggested genotoxic effects of enniatins and beauvericin (Fraeyman et al. 2017). Of course, the impact of mixtures of mycotoxins is now receiving more attention, especially in relation to the potential of synergistic impacts.

In the present study, the occurrence of fusaric acid and fusarin $C$ in the GM and the non-GM maize was low. Previously, fusaric acid and fusarin $\mathrm{C}$ contamination of maize was found in at least $50 \%$ of the samples analysed by Oliveira et al. (2017) from Brazilian maize, whereas fusarin $C$ has been demonstrated to have mutagenic activity and several immunosuppressive effects comparable with those of $\mathrm{AFB}_{1}$ and sterigmatocystin (Cantalejo et al. 1999). Fusaric acid showed low to moderate toxicity, although there are concerns since it might be synergistic with other co-occurring mycotoxins (Bacon et al. 1996).

Despite the higher frequency of isolation of Penicillium spp. in the maize samples, regulated mycotoxins were not detected. The major Penicillia in cereals (e.g. P. verrucosum) prefers cooler temperatures $\left(<25^{\circ} \mathrm{C}\right)$ and intermediate moisture conditions for ochratoxin A production (Cairns-Fuller et al. 2005) than those occurring in maize cultivation areas of Brazil, and this may explain the absence of this or other related toxins. However, a considerable number of emerging metabolites were 
Table 3 Mycotoxins and related secondary metabolites $\left(\mu \mathrm{g} \cdot \mathrm{kg}^{-1}\right)$ found in the GM and non-GM maize cultivars using LC-MS/MS.

\begin{tabular}{|c|c|c|c|c|c|c|c|c|c|c|c|c|c|}
\hline Group & Compounds & $\begin{array}{l}\text { AS } \\
1555 \\
\text { CON* }\end{array}$ & $\begin{array}{l}\text { AS } \\
1555 \\
\text { PRO•• }\end{array}$ & $\begin{array}{l}\text { BM- } \\
709 \\
\mathrm{CON}^{*}\end{array}$ & $\begin{array}{l}\text { BM-709 } \\
\text { PRO }_{2} \bullet \bullet\end{array}$ & $\begin{array}{l}\text { CD- } \\
384 \\
\mathrm{CON}^{*}\end{array}$ & $\begin{array}{l}\text { CD- } \\
384 \\
\text { PW•• }\end{array}$ & $\begin{array}{l}\text { M20- } \\
\text { A78 } \\
\text { CON* }\end{array}$ & $\begin{array}{l}\text { M20- } \\
\text { A78 } \\
\text { PW•• }\end{array}$ & $\begin{array}{l}\mathrm{P} 2530 \\
\mathrm{CON}^{*}\end{array}$ & $\begin{array}{l}\text { P2530 } \\
\text { Hx•• }\end{array}$ & $\begin{array}{l}\text { P30F3 } \\
\text { CON* }\end{array}$ & $\begin{array}{l}\text { P30F53 } \\
\mathrm{H} \bullet \bullet\end{array}$ \\
\hline \multirow[t]{11}{*}{ A } & ${ }^{\star}$ Fumonisin $\mathrm{B}_{1}$ & 110 & - & 1060 & 125 & 6480 & - & 168 & - & - & 24.7 & 5550 & 148 \\
\hline & ${ }^{\star}$ Fumonisin $\mathrm{B}_{2}$ & 26.4 & - & 464 & 46.8 & 2050 & - & 53.3 & 16.9 & 16.3 & - & 2700 & 28.0 \\
\hline & Fumonisin $\mathrm{B}_{3}$ & 21.4 & - & 82.5 & - & 1060 & - & - & - & - & - & 666 & - \\
\hline & Fumonisin $\mathrm{B}_{4}$ & - & - & 137 & 19.7 & 1120 & - & 25.1 & - & 11.5 & - & 891 & - \\
\hline & H. Fumonisin $B_{1}$ & 5.5 & - & - & - & 133.5 & - & - & - & - & - & 70.0 & 59.6 \\
\hline & Fusarin C & 26.1 & - & - & - & 1050 & - & - & - & - & - & 363 & - \\
\hline & Bikaverin & 21.8 & - & 17.0 & - & 957 & - & - & - & - & - & 170 & 26.4 \\
\hline & Beauvericin & - & - & - & - & - & - & - & - & - & - & - & - \\
\hline & Fusaric acid & - & - & - & - & 63.4 & - & - & - & - & - & - & - \\
\hline & Fusarinolic acid & - & - & - & - & 727 & - & - & - & - & - & 208 & - \\
\hline & Equisetin & - & - & 0.8 & 3.2 & - & - & - & 26.8 & - & 1.2 & - & - \\
\hline \multirow[t]{2}{*}{ B } & Alternariol & - & - & - & - & 2.9 & - & - & - & - & - & 8.2 & 8.5 \\
\hline & Alternariolmethylether & 1.9 & - & - & - & 1.6 & 0.2 & - & - & - & - & 3.3 & 1.8 \\
\hline \multirow[t]{9}{*}{$\mathrm{C}$} & Berkedrimane B & 3.6 & - & - & - & 1.2 & - & - & - & - & - & 21.6 & 11.2 \\
\hline & Chrodrimanin & - & - & - & - & 65.7 & - & - & - & - & - & 551 & 247 \\
\hline & Demethylsulochrin & 1.7 & - & - & - & 3.9 & - & - & - & - & - & 2.5 & 8.8 \\
\hline & Penicillide & 8.3 & - & - & - & 26.1 & - & - & - & - & - & 36.4 & 28.7 \\
\hline & Pinselin & - & - & - & - & - & - & - & - & - & - & 1.8 & 6.8 \\
\hline & Purpactin A & 5.5 & 1.0 & - & - & 3.4 & 1.0 & - & - & - & - & 22.1 & 43.3 \\
\hline & Questiomycin A & 122 & 29.3 & 10.1 & - & 89.3 & 31.5 & 7.5 & 4.7 & 479 & 12.6 & 126 & 70.4 \\
\hline & Rugulovasine A & 17.7 & 2.5 & 2.3 & - & 7.0 & 33.7 & - & 8.0 & 5.4 & 2.5 & 2.6 & 7.7 \\
\hline & Dehydroaustinol & - & 2.7 & - & - & 5.6 & - & - & - & - & - & 40.1 & 16.1 \\
\hline \multirow[t]{2}{*}{$\mathrm{D}$} & Asperglaucide & 22.6 & 21.3 & 0.1 & - & 1.6 & 16.6 & 0.6 & - & - & - & 0.3 & 53.2 \\
\hline & Asperphenamate & 53.5 & 132 & 0.5 & - & 0.6 & 10.0 & 0.1 & - & - & - & 0.2 & 18.4 \\
\hline \multirow[t]{5}{*}{$\mathrm{E}$} & cyclo(L-Pro-L-Tyr) & 3.1 & 2.6 & 3.8 & 2.2 & - & 1.8 & 1.9 & 5.4 & 1.0 & 2.4 & - & 4.9 \\
\hline & Emodin & 0.3 & - & - & - & 0.4 & - & - & - & - & - & 0.4 & 0.6 \\
\hline & iso-Rhodoptilometrin & 0.5 & 0.2 & - & - & 1.3 & 0.1 & - & - & - & - & 0.8 & 1.4 \\
\hline & N-B-P & 4.0 & 8.8 & - & - & - & - & - & - & - & - & - & 3.1 \\
\hline & Tryptophol & 27.9 & 16.8 & 10.5 & 15.7 & 24.9 & 10.4 & - & 8.2 & - & 14.2 & 26.3 & 20.4 \\
\hline
\end{tabular}

H. Fumonisin $B_{1}$, Hydrolysed fumonisin $\mathrm{B}_{1} ; N-B-P, N$-Benzoyl-Phenylalanine

*Indicates conventional (non-GM) maize line

A Fusarium sp. metabolites

B Alternaria sp. metabolites

C Penicillium sp. metabolites

D Unknown sp. metabolites

E Other species

CON indicates the term "conventional"

- Indicates amounts lower than the limit of detection of the equipment

- Mycotoxins regulated by EU regulation 1881/2006/EC (sum Fumonisin $\mathrm{B}_{1}+\mathrm{B}_{2}=4000 \mu \mathrm{g} \cdot \mathrm{kg}^{-1}$ )

-• Indicates the respective isogenic GM maize line

present in both GM and non-GM cvs. Questiomycin A and rugulovasine A were the metabolites with the highest occurrence in the samples, being present in 90 and $83 \%$, of samples, respectively. The same metabolites were not detected in the maize from Egypt, but their prevalence was high in feed samples, being 68 and 3\%, respectively (Abdallah et al. 2017). Questiomycin A was also detected in many maize samples (94 to 100\%) from Serbia in the 2012 to 2015 seasons (Janić Hajnal et al. 2020). In Brazil, Penicillium spp. metabolites reported in maize have included rugulovasine A, citrinin, 


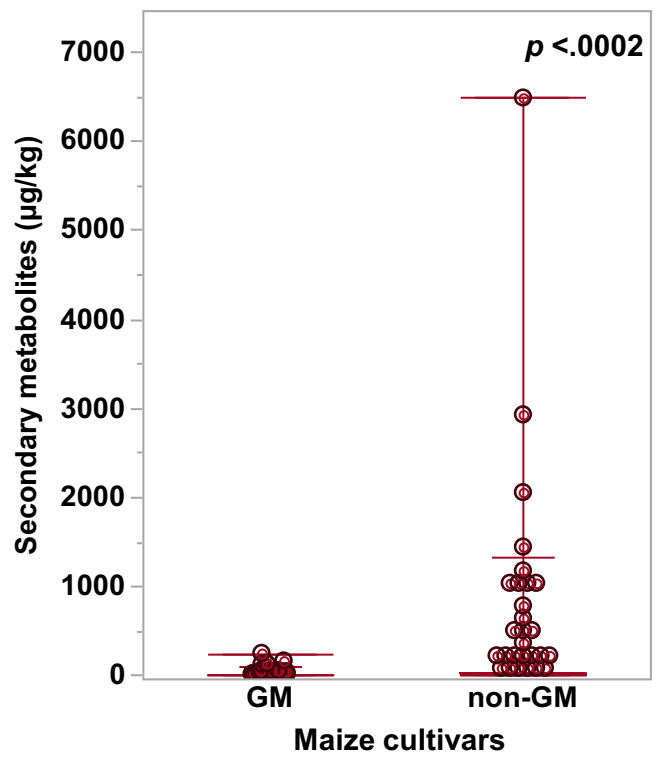

Fig. 4 Overall distribution of all mycotoxin and related secondary metabolites identified from the GM and non-GM maize cultivars. $p<$ 0.05 indicates significant difference between the levels using the Wilcoxon - Each Pair test

mycophenolic acid, andrastin A, curvularin and penicillic acid, although their prevalence was not high (Oliveira et al. 2017).

It is worthwhile highlighting the differences in mycotoxin profiles between the GM and non-GM maize found in this study. This is in contrast to the frequency of fungal isolation which was similar across the cvs. Some studies have suggested that there are lower mycotoxins in GM maize when compared with non-GM cvs due the reduction of insects that represent an important vector for infection by fungal species of the ripening maize cobs. Associations between insect pests and toxigenic fungi are well-known. Mainly Lepidopteran species act as vectors for fungal spores as well as damage the ripening maize kernels, allowing entry of $A$. flavus and other spoilage moulds to infect the cobs (Alma et al. 2005). An effective way to manage Lepidopteran insects and reduce the associated mycotoxin risk has been the use of GM insect-resistant genes (Bt) (Munkvold et al. 1999; Wu 2006). Pellegrino et al. (2018) observed mycotoxin contamination in relation to plants expressing resistance to Lepidoptera (GM Bt) and this suggested that all stacked Cryl Ab hybrids contained significantly less fumonisins and trichothecenes.

Previously, 19 of 23 studies were compared in a review by Ostry et al. (2010) of GM (Bt) maize which concluded that this type of maize was less contaminated with Fusarium mycotoxins (fumonisins, deoxynivalenol, zearalenone) than the conventional control cvs in each case. However, Naef et al. (2006) suggested that $\mathrm{Cry} 1 \mathrm{Ab}$ protein in maize residues has no direct effect on $F$. graminearum and Trichoderma atroviride, but some corresponding $\mathrm{Bt} /$ non-Bt maize hybrids differed more in composition than the Cry protein content alone, which can affect the saprophytic survival of mycotoxigenic fungi on crop residues.
Barroso et al. (2017) assessed the frequency of $F$. verticillioides and the concentration of fumonisins in GM (Bt) and isogenic non-GM hybrids. The GM samples had a lower $F$. verticillioides frequency than non-GM. However, there was no statistical difference between fumonisin contamination when GM $B t$ and non-GM samples were compared. The results suggest that other environmental parameters could possibly trigger fumonisin production during plant development in the field.

Junior et al. (2019) correlated the presence of fumonisins in maize with other factors such as the type of hybrid and environment in four different states of Brazil. It showed that high severity of grains infected with $F$. verticillioides does not always result in more fumonisins. Environments with higher temperatures may influence the production of high concentrations of fumonisin in maize (Rosa Junior et al. 2019). Another study of Brazilian maize indicated that a GM hybrid with insect resistance (DKB390 YG) showed greater genetic resistance to the infection by $F$. verticillioides and fumonisin accumulation when compared with the other evaluated hybrids (da Costa et al. 2018). However, within the hybrids used, no comparisons were made between the GM cv and the direct isogenic non-GM line.

Morphological characteristics of the maize kernels in ripening cobs can affect susceptibility to mycotoxin-producing fungi, either directly or indirectly. Hybrids with a thicker kernel pericarp are usually more resistant than those with a thinner pericarp, which can also contribute to resistance. To reduce mycotoxin risk, hybrid selection criteria should include partial resistance to ear rot diseases, appropriate maturity range, husk coverage characteristics and adaptation to local conditions of abiotic stress (Munkvold 2014). da Costa et al. (2018) demonstrated that delaying harvest for minimising drying costs may increase the risk of mycotoxin contamination in maize in the tropics of Brazil. Sampietro et al. (2009) suggested that kernel factors are involved in resistance to fumonisin accumulation in the maize. Resistance was associated with the outer kernel layers and wax content in most of them. Higher wax content would give a broad-based resistance mechanism in maize kernels against mycotoxin production. However, it cannot completely explain the resistance observed.

In summary, this is the first study comparing the fungal contamination and internal infection of GM and non-GM isogenic maize cvs from Brazil containing genetic traits for both insect resistance and/or herbicide tolerance, not only GM Bt. The fungal diversity of GM and isogenic non-GM maize grain was found to be very similar $(p<0.05)$. The analysis of the targeted metabolomics profiles of the maize cvs by LC-MS/ MS showed higher amounts of Fusarium metabolites that paralleled the high isolation frequency of these species from both GM and non-GM maize grain. Overall, the distribution of mycotoxins and related compounds indicated differences 
between non-GM and GM cvs $(p<0.05)$. GM maize had lower concentrations of different mycotoxins and related secondary metabolites. More detailed studies are now necessary for a better understanding of the potential implications of genetic traits inserted into maize cvs with regard to A. flavus colonisation and aflatoxin contamination.

Funding AMG is the recipient of financial support from the CAPES Foundation, Ministry of Education of Brazil for her PhD (Project BEX 12937/13-4).

\section{Compliance with ethical standards}

Conflict of interest The authors declare that they have no conflicts of interest.

Open Access This article is licensed under a Creative Commons Attribution 4.0 International License, which permits use, sharing, adaptation, distribution and reproduction in any medium or format, as long as you give appropriate credit to the original author(s) and the source, provide a link to the Creative Commons licence, and indicate if changes were made. The images or other third party material in this article are included in the article's Creative Commons licence, unless indicated otherwise in a credit line to the material. If material is not included in the article's Creative Commons licence and your intended use is not permitted by statutory regulation or exceeds the permitted use, you will need to obtain permission directly from the copyright holder. To view a copy of this licence, visit http://creativecommons.org/licenses/by/4.0/.

\section{References}

Abdallah MF, Girgin G, Baydar T, Krska R, Sulyok M (2017) Occurrence of multiple mycotoxins and other fungal metabolites in animal feed and maize samples from Egypt using LC-MS/MS. J Sci Food Agric 97:4419-4428. https://doi.org/10.1002/jsfa.8293

Alberts JF, van Zyl WH, Gelderblom WCA (2016) Biologically based methods for control of fumonisin-producing Fusarium species and reduction of the fumonisins. Front Microbiol 7:548. https://doi.org/ 10.3389/fmicb.2016.00548

Alma A, Lessio F, Reyneri A, Blandino M (2005) Relationships between Ostrinia nubilalis (Lepidoptera: Crambidae) feeding activity, crop technique and mycotoxin contamination of corn kernel in northwestern Italy. Int J Pest Manag 51:165-173. https://doi.org/10.1080/ 09670870500179698

Bacon CW, Porter JK, Norred WP, Leslie JF (1996) Production of fusaric acid by Fusarium species. Appl Environ Microbiol 62:4039-4043. https://doi.org/10.1128/aem.62.11.4039-4043.1996

Baquião AC, Zorzete P, Reis TA, Assunção E, Vergueiro S, Correa B (2012) Mycoflora and mycotoxins in field samples of Brazil nuts. Food Control 28:224-229. https://doi.org/10.1016/j.foodcont.2012. 05.004

Barroso VM, Rocha LO, Reis TA, Reis GM, Duarte AP, Michelotto MD, Correa B (2017) Fusarium verticillioides and fumonisin contamination in $\mathrm{Bt}$ and non-Bt maize cultivated in Brazil. Mycotoxin Res 33: 121-127. https://doi.org/10.1007/s12550-017-0271-4

Battilani P, Formenti S, Ramponi C, Rossi V (2011) Dynamic of water activity in maize hybrids is crucial for fumonisin contamination in kernels. J Cereal Sci 54:467-472. https://doi.org/10.1016/j.jcs.2011. 08.014
Battilani P, Camardo Leggieri M, Rossi V, Giorni P (2013) AFLA-maize, a mechanistic model for Aspergillus flavus infection and aflatoxin B1 contamination in maize. Comput Electron Agric 94:38-46. https://doi.org/10.1016/j.compag.2013.03.005

Bordin K, Rottinghaus GE, Landers BR, Ledoux DR, Kobashigawa E, Corassin CH, Oliveira CAF (2015) Evaluation of fumonisin exposure by determination of fumonisin B1 in human hair and in Brazilian corn products. Food Control 53:67-71. https://doi.org/ 10.1016/J.FOODCONT.2015.01.011

Cairns-Fuller V, Aldred D, Magan N (2005) Water, temperature and gas composition interactions affect growth and ochratoxin A production by isolates of Penicillium verrucosum on wheat grain. J Appl Microbiol 99:1215-1221. https://doi.org/10.1111/j.1365-2672. 2005.02695.x

Caldas EDJ, Oliveira AN (2012) Exposure to toxic chemicals in the diet: is the Brazilian population at risk? J Expo Sci Environ Epidemiol 22:1-15. https://doi.org/10.1038/jes.2011.35

Cantalejo MJ, Torondel P, Amate L, Carrasco JM, Hernández E (1999) Detection of fusarin $\mathrm{C}$ and trichothecenes in Fusarium strains from Spain. J Basic Microbiol 39:143-153. https://doi.org/10.1002/ (SICI)1521-4028(199906)39:3<143::AID-JOBM143>3.0.CO;2-U

Chan Y, Walmsley RP (1997) Learning and understanding the KruskalWallis one-way analysis-of-variance-by-ranks test for differences among three or more independent groups. Phys Ther 77:1755-1762

da Costa RV, Queiroz VAV, Cota LV, da Silva DD, Lanza FE, de Almeida REM, Pereira AA, Alves RR, Campos LJM (2018) Delaying harvest for naturally drying maize grain increases the risk of kernel rot and fumonisin contamination. Trop Plant Pathol 43: 452-459. https://doi.org/10.1007/s40858-018-0234-0

EC - European Commission (2006) Commission regulation (EC) No 1881/2006 of 19 December 2006 setting maximum levels for certain contaminants in foodstuffs. In: Off. J. Eur. Last consolidated version available from: Union. https://eur-lex.europa.eu/legal-content/DE/ AUTO/?uri=CELEX:02006R1881-20180319. Accessed 12 Oct 2020

EFSA - CONTAM Panel (EFSA Panel on Contaminants in the Food Chain) (2014) Scientific opinion on the risks to human and animal health related to the presence of beauvericin and enniatins in food and feed. EFSA J 12:3802

Fraeyman S, Croubels S, Devreese M, Antonissen G (2017) Emerging fusarium and alternaria mycotoxins: Occurrence, toxicity and toxicokinetics. Toxins (Basel) 9:1-26. https://doi.org/10.3390/ toxins 9070228

Garcia-Cela E, Kiaitsi E, Medina A et al (2018) Interacting environmental stress factors affects targeted metabolomic profiles in stored natural wheat and that inoculated with $F$. graminearum. Toxins (Basel) 10 : 56. https://doi.org/10.3390/toxins10020056

Gasperini AM (2019) Fungal diversity, pest damage and biocontrol of aflatoxins in GM and conventional Brazilian maize cultivars under existing and future climate change scenarios. $\mathrm{PhD}$ Thesis. Cranfield University.

Gasperini AM, Rodriguez-Sixtos A, Verheecke-Vaessen C, Garcia-Cela E, Medina A, Magan N (2019) Resilience of biocontrol for aflatoxin minimization strategies: climate change abiotic factors may affect control in Non-GM and GM-Maize cultivars. Frontiers in Microbiology 10. https://doi.org/10.3389/fmicb.2019.02525

ISAAA (2017) Global status of commercialized biotech/GM crops in 2017: biotech crop adoption surges as economic benefits accumulate in 22 years. ISAAA $1-153$

Janić Hajnal E, Kos J, Malachová A, Steiner D, Stranska M, Krska R, Sulyok M (2020) Mycotoxins in maize harvested in Serbia in the period 2012-2015. Part 2: non-regulated mycotoxins and other fungal metabolites. Food Chem 317:126409. https://doi.org/10.1016/j. foodchem.2020.126409 
Jestoi M (2008) Emerging Fusarium-mycotoxins fusaproliferin, beauvericin, enniatins, and moniliformin - a review. Crit Rev Food Sci Nutr 48:21-49. https://doi.org/10.1080/10408390601062021

Junior OFR, Dalcin MS, Nascimento VL et al (2019) Fumonisin production by Fusarium verticillioides in maize genotypes cultivated in different environments. Toxins (Basel) 11:215. https://doi.org/10. 3390/toxins11040215

Kawashima LM, Valente Soares LM (2006) Incidência de fumonisina B1, aflatoxinas B1, B2, G1 e G2, ocratoxina A e zearalenona em produtos de milho. Ciência e Tecnol Aliment 26:516-521. https:// doi.org/10.1590/S0101-20612006000300005

Lacey J (1989) Pre- and post-harvest ecology of fungi causing spoilage of foods and other stored products. Soc Appl Bacteriol Symp Ser 18: $11 \mathrm{~S}-25 \mathrm{~S}$

Lanza FE, Zambolim L, Costa RV, Figueiredo JEF, Silva DD, Queiroz VAV, Guimarães EA, Cota LV (2017) Symptomatological aspects associated with fungal incidence and fumonisin levels in corn kernels. Trop Plant Pathol 42:304-308. https://doi.org/10.1007/ s40858-017-0148-2

Malachová A, Sulyok M, Beltrán E, Berthiller F, Krska R (2014) Optimization and validation of a quantitative liquid chromatographytandem mass spectrometric method covering 295 bacterial and fungal metabolites including all regulated mycotoxins in four model food matrices. J Chromatogr A 1362:145-156. https://doi.org/10.1016/j. chroma.2014.08.037

Mohale S, Medina A, Rodríguez A, Sulyok M, Magan N (2013) Mycotoxigenic fungi and mycotoxins associated with stored maize from different regions of Lesotho. Mycotoxin Res 29:209-219. https://doi.org/10.1007/s12550-013-0176-9

Moreno EC, Garcia GT, Ono MA, Vizoni É, Kawamura O, Hirooka EY, Ono EYS (2009) Co-occurrence of mycotoxins in corn samples from the Northern region of Paraná State, Brazil. Food Chem 116: 220-226. https://doi.org/10.1016/j.foodchem.2009.02.037

Munkvold G (2014) Crop management practices to minimize the risk of mycotoxins contamination in temperate-zone maize. In: Leslie JF, Logrieco A (eds) Mycotoxin reduction in grain chains. John Wiley \& Sons, Chichester, pp 59-77

Munkvold GP, Desjardins AE (1997) Fumonisins in maize: can we reduce their occurence? Plant Dis 81:556-565. https://doi.org/10. 1094/PDIS.1997.81.6.556

Munkvold GP, Hellmich RL, Rice LG (1999) Comparison of fumonisin concentrations in kernels of transgenic Bt maize hybrids and nontransgenic hybrids. Plant Dis 83:130-138. https://doi.org/10. 1094/PDIS.1999.83.2.130

Naef A, Zesiger T, Défago G (2006) Impact of transgenic Bt maize residues on the mycotoxigenic plant pathogen and the biocontrol agent. J Environ Qual 35:1001-1009. https://doi.org/10.2134/ jeq2005.0334
Oliveira MS, Rocha A, Sulyok M, Krska R, Mallmann CA (2017) Natural mycotoxin contamination of maize (Zea mays L.) in the South region of Brazil. Food Control 73:127-132. https://doi.org/ 10.1016/J.FOODCONT.2016.07.033

Ostry V, Ovesna J, Skarkova J, Pouchova V, Ruprich J (2010) A review on comparative data concerning Fusarium mycotoxins in Bt maize and non-Bt isogenic maize. Mycotoxin Res 26:141-145. https://doi. org/10.1007/s12550-010-0056-5

Pellegrino E, Bedini S, Nuti M, Ercoli L (2018) Impact of genetically engineered maize on agronomic, environmental and toxicological traits: A meta-analysis of 21 years of field data. Sci Rep 8:3113. https://doi.org/10.1038/s41598-018-21284-2

Peluque E, Neres NB, Michelin EC, Reis TA, Rosim RE, Oliveira CAF, Sousa RLM, Corrêa B, Fernandes AM (2014) Fumonisin B1 in cereal mixtures marketed in Brazil. Food Addit Contam Part B 7: 46-48. https://doi.org/10.1080/19393210.2013.841294

Piacentini KC, Rocha LO, Fontes LC, Carnielli L, Reis TA, Corrêa B (2017) Mycotoxin analysis of industrial beers from Brazil: The influence of fumonisin B1 and deoxynivalenol in beer quality. Food Chem 218:64-69. https://doi.org/10.1016/j.foodchem.2016.09.062

Salay E, Zerlotti Mercadante A (2002) Mycotoxins in Brazilian corn for animal feed: occurrence and incentives for the private sector to control the level of contamination. Food Control 13:87-92. https://doi. org/10.1016/S0956-7135(01)00072-X

Sampietro DA, Vattuone MA, Presello DA, Fauguel CM, Catalán CAN (2009) The pericarp and its surface wax layer in maize kernels as resistance factors to fumonisin accumulation by Fusarium verticillioides. Crop Prot 28:196-200. https://doi.org/10.1016/j. cropro.2008.09.010

Sulyok M, Stadler D, Steiner D, Krska R (2020) Validation of an LC-MS/ MS-based dilute-and-shoot approach for the quantification of $>500$ mycotoxins and other secondary metabolites in food crops: challenges and solutions. Anal Bioanal Chem 412:2607-2620. https:// doi.org/10.1007/s00216-020-02489-9

Vidal N, Barbosa H, Jacob S, Arruda M (2015) Comparative study of transgenic and non-transgenic maize (Zea mays) flours commercialized in Brazil, focussing on proteomic analyses. Food Chem 180: 288-294. https://doi.org/10.1016/j.foodchem.2015.02.051

Windham GL, Williams WP, Davis FM (1999) Effects of the Southwestern corn borer on Aspergillus flavus kernel infection and aflatoxin accumulation in maize hybrids. Plant Dis 83:535-540. https://doi.org/10.1094/PDIS.1999.83.6.535

Wu F (2006) Mycotoxin reduction in Bt corn: Potential economic, health, and regulatory impacts. Transgenic Res 15:277-289. https://doi.org/ $10.1007 / \mathrm{s} 11248-005-5237-1$

Publisher's note Springer Nature remains neutral with regard to jurisdictional claims in published maps and institutional affiliations. 